\title{
Health Knowledge and Health Promoting Lifestyle Among Women of Childbearing age in Shiraz
}

\author{
Aliyar Ahmadi ${ }^{1,} ;$ Fatemeh Roosta $^{1}$ \\ ${ }^{1}$ Department of Sociology and Social Planning, Shiraz University, Shiraz, IR Iran \\ ${ }^{*}$ Corresponding author: Aliyar Ahmadi, Department of Sociology and Social Planning, Shiraz University, Shiraz, IR Iran. Tel: +98- 9126965189, Fax: +98-7136289661, \\ E-mail:ahmadi@rose.shirazu.ac.ir, ahmadi.aliyar@gmail.com
}

Received: November 15, 2014; Accepted: May 5, 2015

\begin{abstract}
Background: Health promotion is receiving an ever increasing attention regarding its prominent role in health of population. Health promoting lifestyle could be due, in some part, to enhancing knowledge about healthy behaviors.

Objectives: Due to the importance of healthy lifestyle in current situation of chronic diseases in Iranian society, the aim of this study was to determine the correlates of health promoting life style with a special emphasis on the role of health knowledge among women of reproductive age.

Patients and Methods: This cross-sectional study was carried out on a sample of 392 women of child bearing age (15 - 49 years) in 2013 in the city of Shiraz, southern Iran. The participants were selected through random cluster sampling. The scale for health promotion lifestyle was Walker's Health Promoting lifestyle Profile (HPLP), which encompasses six healthy lifestyle dimensions including health selfresponsibility, nutrition, physical activity, stress management, interpersonal relationships and spiritual growth.

Results: The results of the study indicated a significant association between health knowledge $(r=0.225, P=0.000)$, rate of study in health matters $(r=0.341, P=0.000)$, women's education $(r=0.109, P=0.035)$, husbands' education $(r=0.182, P=0.005)$, and socio-economic class (Spearman' rho $=0.154, \mathrm{P}=0.000$ ) and Health Promoting lifestyle (HPLS). In addition, age and education affected HPLS through health knowledge. There was no significant association between age, age at marriage, family size, marital status, experience of abortion and occupation with Health Promoting lifestyle.

Conclusions: Knowledge automatically creates the desired changes in behavior. Health professionals and health education programs have to increase awareness of healthy lifestyle behaviors that enables people to apply this knowledge in their everyday lives. Therefore, the goal of health policy should be promoting the health knowledge of the population.
\end{abstract}

Keywords: Health Promotion; Lifestyle; Health Behavior; Women

\section{Background}

The most important dimension of World Health Organization's goals and strategies in the plan of "health for all" is emphasizing "Health Promotion" (1). Health promotion is receiving an ever increasing attention regarding the prominent role it plays in the health of the population. The high costs of health care have necessitated a shift in the emphasis of care to the prevention of diseases, rather than strictly treating the diseases (2). This importance of health promotion lifestyle is due to change in nature of health problem as stated by health scientists "Epidemiologic Transition". The health promotion principles are based on human rights, seeing people as active participants (3).

Living a healthy lifestyle, with emphasis on the behavioral aspect, is not necessarily up to the individuals, but is affected by various factors such as socio-economic status, level of education, family, social networks, gender, age and interpersonal relationships $(4,5)$. Altogether, a supportive environment which enables people to live a healthy life, is of utmost importance for the populations' well-being (6). A literature review carried out by Gillis (7) indicated that self-efficacy, social support, perceived benefits, self-concepts and perceived barriers are the strongest predictors of a health promoting lifestyle. In addition, the literature review indicates that healthy lifestyle is also influenced by marital $(8,9)$, and employment status (10), family size (11), education (12,13), self- efficacy (14), and knowledge about healthy lifestyle $(15,16)$.

Health knowledge hinges health literacy. Over the past decade, increased interest in health literacy, defined as capacity of individuals to obtain, process and understand the basic health information and services needed to make appropriate health decisions (17), has reinforced the movement to empower health care users (18). Some studies investigated how health literacy affects patients' knowledge of disease, health status and health service utilization $(19,20)$. Those who reported a higher medical knowledge had higher knowledge of interpersonal relationship and a lower level of stress $(19,21)$. On the other hand, some studies indicate lack of association between

Copyright (C2015, Health Policy Research Center, Shiraz University of Medical Sciences. This is an open-access article distributed under the terms of the Creative Commons Attribution-NonCommercial 4.0 International License (http://creativecommons.org/licenses/by-nc/4.0/) which permits copy and redistribute the material just in noncommercial usages, provided the original work is properly cited. 
Ahmadi A et al.

knowledge and healthy lifestyle behaviors $(22,23)$. Health knowledge can be promoted via health education. The purpose of health education is to inform and motivate individuals to actively care for their own health. Health education programs enable individuals to gain knowledge, form points of view and behavioral pattern for a healthy lifestyle (24).

\section{Objectives}

Research regarding the effect of health knowledge on health promoting lifestyle in Iran is scarce. Based on the results of the aforementioned studies and due to the importance of healthy lifestyle in current situation of chronic diseases in the Iranian society, it is essential to investigate the correlates of the healthy lifestyle. Therefore, this study was conducted to determine the correlates of health promoting lifestyle with a special emphasis on the role of health knowledge among women of reproductive age.

\section{Patients and Methods}

\subsection{Data and Sample}

The current study is a cross-sectional survey which aims at investigating determinants of health promotion lifestyle. A sample of 392 women of child bearing age (1549 years-old) in Shiraz (based on Cochran's sample size formula with confidence level of $95 \%$ and alpha error of 0.05 ) were interviewed in 2013 via self-administered questionnaires. The participants were selected through random cluster sampling.

Participants received a three-sectioned questionnaire. The validity of the questionnaire was assured using face validity. Furthermore, a pilot study was conducted in order to gain the internal validity of the questionnaire and also to determine whether the questions were entirely understandable. The first Part of the questionnaire contained questions regarding the socio-demographic characteristics of the participants. The second part consisted of questions to identify health promoted life-style of women and the last part included a Likert-scale questionnaire to measure health knowledge. The scale for health promotion lifestyle was Walker's Health Promoting lifestyle Profile (HPLP), a well-established instrument in the health promotion literature. In addition, the HPLP tool has shown to have high reliability and validity (25). Validity and reliability of the Persian version of the questionnaire was also proven to be high (26).

\subsection{Statistical Analysis}

Cronbach's alpha technique was used to determine the reliability of the questionnaire, resulting in an alpha of 0.64 and 0.87 in scales (Table 1). Confirmatory factor analysis with a significant KMO and Bartletts test (Table 1) was used to construct the scale of variables of health promotion lifestyle and health knowledge.

The scale encompasses six healthy lifestyle dimensions including health self-responsibility, nutrition, physical activity, stress management, interpersonal relationships and spiritual growth.

Statistical analysis was completed using SPSS version 18. The descriptive analysis provided detailed characteristics of the sample. In inferential analyses, Pearson correlation, Spearman rho, t-test and ANOVA were applied to determine the relationships between the dependent variable, health Promoting Lifestyle (HPLS) and independent variables including health knowledge, rate of study in health matters, women's education, husbands' education, socio-economic class, age, age at marriage, family size, marital status, experience of abortion and occupation. The alpha level $(\alpha)$ for rejection of null-hypotheses was set at 0.05 (P value $\geq 0.05$ ). Finally, a Multiple Regression Model was run to assess the importance of each variable in explaining the dependent variable. The result was indicated in Path Diagram. The diagram is obtained from Path analysis, which is a straightforward extension of multiple regression, and aims at providing estimates of the magnitude and significance of causal connections between sets of variables.

\section{Results}

Table 2 presents the descriptive statistics of the variables in the current investigation. The age of participants ranged from 15 to 49 years, with a mean of $30.08 \pm 9.03$. The mean of family size was $3.8 \pm 1.34$. Among participants the mean for Children Ever Born (CEB) was 1.83 \pm 1.1 . In the sample, $61 \%$ of participants were married, of whom $24 \%$ had experienced abortion. As for the status of the participants, $35.6 \%$ of individuals were employed, $17.2 \%$ were student, $41.7 \%$ were housewives, and $5.5 \%$ were unemployed.

Table 1. Results of Factor Analysis and Cronbach's Alpha for Scales of Study

\begin{tabular}{lcc}
\hline Indices & Health Knowledge & Health Promoting Lifestyle \\
\hline Eigenvalue & 2.04 & 2.35 \\
Variance Explained, \% & 51 & 39 \\
K-M-O Measure & 0.71 & 0.73 \\
Bartlett's test & $241,(\mathrm{P}=0.000)$ & $338,(\mathrm{P}=0.000)$ \\
Cronbach's alpha & 0.64 & 0.87 \\
\hline
\end{tabular}


The mean and standard deviation for the dependent variable, health promoting life style, was $51.51 \pm 19.2$. The Kolmogorove-Smirnove test showed a significant normal distribution of dependent variable (0.858).

Table 3 indicates the association between demographic and socio-economic variables with HPLS. There is a significant linear correlation between variables of study in health matters $(r=0.341$, P value $=0.000)$, Health knowledge $(r=0.225$, P value $=0.000)$, women's education $(r=$ 0.109 , $\mathrm{P}$ value $=0.035)$, husbands' education $(\mathrm{r}=0.182$, $\mathrm{P}$ value $=0.005$ ), socio-economic class (Spearman $r h o=0.154$, P-value $=0.000$ ) and HPLS. There is no significant association between age, age at marriage, family size, marital status, experience of abortion and occupation with HPLS.

\begin{tabular}{|c|c|}
\hline Variables & Value Statistics \\
\hline Age, yr & $30.08 \pm 9.03$ \\
\hline $15-25$ & $109(28.5)$ \\
\hline $26-35$ & $148(38.7)$ \\
\hline $36-49$ & $125(32.7)$ \\
\hline \multicolumn{2}{|l|}{ Marital Status } \\
\hline Married & $239(61)$ \\
\hline Unmarried & $153(39)$ \\
\hline Family Size & $(3.8 \pm 1.34)$ \\
\hline $1-2$ & $68(17.9)$ \\
\hline $3-4$ & $213(56.2)$ \\
\hline $4+$ & $98(25.9)$ \\
\hline Children Ever Born & $(1.83 \pm 1.11)$ \\
\hline 0 & $15(7.8)$ \\
\hline $1-2$ & $142(74.0)$ \\
\hline $3-4$ & $29(15.1)$ \\
\hline $5+$ & $6(3.1)$ \\
\hline \multicolumn{2}{|l|}{ Experience of Abortion } \\
\hline Experienced & $55(24)$ \\
\hline Inexperienced & $180(76)$ \\
\hline Education & $(13.8 \pm 3.1)$ \\
\hline Primary & $41(10.6)$ \\
\hline Secondary & $107(27.6)$ \\
\hline University & $240(61.9)$ \\
\hline \multicolumn{2}{|l|}{ Occupation } \\
\hline Employed & $122(35.6)$ \\
\hline Student & $59(17.2)$ \\
\hline Housewife & $143(41.7)$ \\
\hline Unemployed & $19(5.5)$ \\
\hline \multicolumn{2}{|l|}{ Socio-economic Class } \\
\hline Low & $14(3.6)$ \\
\hline Middle-low & $126(33.3)$ \\
\hline Middle-high & $228(60.4)$ \\
\hline High & $10(2.6)$ \\
\hline Health Promoting Lifestyle (HPLS) & $51.51 \pm 19.2$ \\
\hline $0-20$ & $25(6.4)$ \\
\hline $21-40$ & $79(20.1)$ \\
\hline $41-60$ & $164(41.8)$ \\
\hline $61-80$ & $94(24.1)$ \\
\hline $81-100$ & $29(7.5)$ \\
\hline
\end{tabular}

\footnotetext{
${ }^{\mathrm{a}}$ Kolmogorove-Smirnov for Normality test $=0.858, \mathrm{P}=0.454$.

b Kolmogorove-Smirnov Test of Normality indicates Normal Distribution.
}

Table 3. Association between Demographic Variables and HPLS

\begin{tabular}{lccc}
\hline Variables & Test & Value & PValue \\
\hline Health education & Pearson & 0.341 & 0.000 \\
\hline Heath knowledge & Pearson & 0.225 & 0.000 \\
\hline Husband's education & Pearson & 0.182 & 0.005 \\
\hline Socio-economic class & Spearman' rho & 0.154 & 0.000 \\
\hline Education & Pearson & 0.109 & 0.035 \\
\hline Number of Children $($ CEB $)$ & Pearson & 0.108 & 0.131 \\
\hline Age at marriage & Pearson & 0.027 & 0.686 \\
\hline Age & Pearson & 0.018 & 0.725 \\
\hline Family size & Pearson & 0.015 & 0.767 \\
\hline Marital status & t-test & -1.132 & 0.188 \\
\hline Experience of abortion & t-test & 0.281 & 0.779 \\
\hline Occupation & ANOVA & 0.956 & 0.455 \\
\hline
\end{tabular}

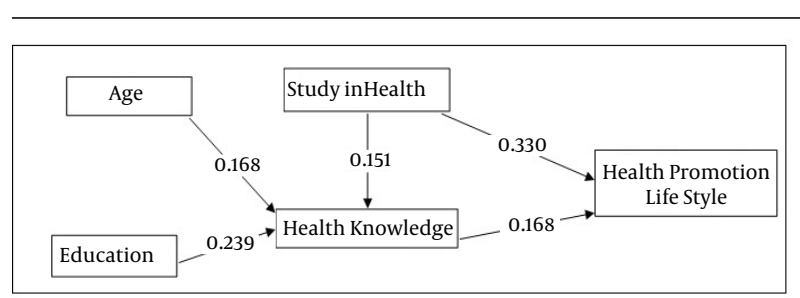

Figure 1. Model Specifying the Relationship Between Health Knowledge and Health Promoting Lifestyle

Figure 1 reveals the causal model specified by path analysis. The age, education and health education, affected health knowledge ( $\beta=0.168,0.239$ and 0.150 for age, education, and health education, respectively). Health knowledge and health education affected HPLS with Beta values of 0.168 and 0.330 , respectively.

\section{Discussion}

Numerous studies have been conducted on the indisputable impact of health knowledge and health education on health behavior worldwide (20). The present study analyzed the relationship between health promoting lifestyle and health knowledge, besides demographic and socio-economic factors. The study indicated that low knowledge in health matters is linked to poor health promoting lifestyle. In addition, simultaneous increase in the rate of health knowledge and HPLS was achieved by consulting books, magazines and newspapers in relation to health concepts.

The study indicated no direct association between age and HPLS, although, age affected dependent variables through health knowledge. In other words, women of higher age groups had more knowledge about the importance of health behaviors such as nutrition, exercise and socialization.

Also the study revealed that education affects HPLS via health knowledge. Some studies have confirmed the positive effect of education on health knowledge (12). 
Moreover, health education has several implications in improving health promotion policies and programs to reduce the risk factors in the population. The results suggest that health professionals need to increase awareness of healthy lifestyle behaviors through implementing health education programs and applying them in their everyday lives.

The path analysis shows that after controlling the effect of other independent variables, those who expressed higher knowledge of health and assigned more time to read health related documents had a higher healthy lifestyle score. Additionally, health knowledge is an intermediate variable linking age and education to the dependent variable.

Reading about health related subjects was the most important predictor of HPLS. This variable showed a significant effect on HPLS both directly and indirectly through health knowledge. The effect of reading about health on healthy lifestyle is documented in literature review.

The goal of health policy should be promoting the health knowledge of the population. Knowledge automatically creates the desired changes in behavior. In reality, formal education and training people in health-related areas help communities change their current behavior. Therefore, mass health educational activities could help the development of health knowledge. Health related curriculum of schools and health promoting programs in the universities and mass media provide opportunities for young people to improve their knowledge and insight, and acquire a healthy lifestyle. The policy makers should plan for active participation of parents to improve the youth's knowledge that affects their health- related behaviors.

\section{Acknowledgements}

The authors would like to thank Ms. Zeinab Mohammadizade for her valued assistance in data gathering.

\section{Financial Disclosure}

The authors declare that they have no financial associations that may pose a conflict of interests in connection with the submitted article. The article is part of an M. A dissertation (IRDC no: 2126922) carried out in Shiraz University, to which authors are affiliated.

\section{References}

1. Sonmezer H, Cetinkaya F, Nacar M. Healthy life-style promoting behaviour in Turkish women aged 18-64. Asian Pac J Cancer Prev. 2012;13(4):1241-5.

2. Adams MH, Bowden AG, Humphrey DS, McAdams LB. Social support and health promotion lifestyles of rural women. Online $J$ Rural Nurs Health Care. 2000;1(1):28-40.

3. Voncina L, Brborovic O, Pavlekovic G. Health Promotion Conferences and Key documents. health promotion and disease prevention. 2007.

4. Fong CW, Bhalla V, Heng D, Chua AV, Chan ML, Chew SK. Educational inequalities associated with health-related behav- iours in the adult population of Singapore. Singapore Med J 2007;48(12):1091-9.

5. Paulik E, Boka F, Kertesz A, Balogh S, Nagymajtenyi L. Determinants of health-promoting lifestyle behaviour in the rural areas of Hungary. Health Promot Int. 2010;25(3):277-88.

1. Premik M, Pavlekovic G, Zaletel Kragelj L, Donev D. Healthy Public Policy. Donev D, Pavleković G, Zaletel-Kragelj L. editor. : Hans Jacobs publishing company; 2007.

2. Gillis AJ. Determinants of a health-promoting lifestyle: an integrative review. JAdv Nurs. 1993;18(3):345-53.

3. Larouche R. Determinants of college students' health-promoting lifestyles. Clin Excell Nurse Pract. 1998;2(1):35-44.

4. Saravi FK, Navidian A, Rigi S, Montazeri A. Comparing healthrelated quality of life of employed women and housewives: a cross sectional study from southeast Iran. BMC Women's Health. 2012;12(1):41.

5. Frank-Stromborg M, Pender NJ, Walker SN, Sechrist KR. Determinants of health-promoting lifestyle in ambulatory cancer patients. So Sci Med. 1990;31(10):1159-68.

6. Premik M, Pavlekovic G, Zaletel Kragelj L, Donev D. Health promotion and disease prevention. In: Donev D, Pavleković G, ZaletelKragelj L., editor. Healthy Public Policy. Vol. 40. Hans Jacobs publishing company; 2007. pp. 40-51.

7. Jackson ES, Tucker CM, Herman KC. Health value, perceived social support, and health self-efficacy as factors in a health-promoting lifestyle.J Am Coll Health. 2007;56(1):69-74.

8. Avazeh A, Jafari N, Mazloomzadeh S. Knowledge level attitude and performance of women on diet and exercise and their relation with cardiovascular diseases risk factors. Zanjan Univ Med Sci J. 2010;18(71):51-60.

9. Imanipour M, Bassampour S, Haghani H. Relationship between Preventive Behaviors and Knowledge Regarding Cardiovascular Diseases. Hayat. 2009;14(2):41-9.

10. Williams MV, Davis T, Parker RM, Weiss BD. The role of health literacy in patient-physician communication. Fam Med. 2002;34(5):383-9.

11. Nutbeam D. Health literacy as a public health goal: a challenge for contemporary health education and communication strategies into the 21st century. Health Promot Int. 2000;15(3):259-67.

12. Baker DW, Parker RM, Williams MV, Clark WS, Nurss J. The relationship of patient reading ability to self-reported health and use of health services. Am J Public Health. 1997;87(6):1027-30.

13. Lee SY, Arozullah AM, Cho YI. Health literacy, social support, and health: a research agenda. Soc Sci Med. 2004;58(7):1309-21.

14. Coulson I, Strang V, Marino R, Minichiello V. Knowledge and lifestyle behaviors of healthy older adults related to modifying the onset of vascular dementia. Arch Gerontol Geriatr. 2004;39(1):43-58.

15. Kelly JA, St Lawrence JS, Brasfield TL, Lemke A, Amidei T, Roffman RE, et al. Psychological factors that predict AIDS highrisk versus AIDS precautionary behavior. J Consult Clin Psychol. 1990;58(1):117-20.

16. Steptoe A, Wardle J, Fuller R, Holte A, Justo J, Sanderman R, et al. Leisure-time physical exercise: prevalence, attitudinal correlates, and behavioral correlates among young Europeans from 21 countries. Prev Med.1997;26(6):845-54.

17. Bigec M, Kragelj LZ. Disease prevention in pre-school children Health Promot Dis Prev . 2007:380.

18. Walker SN, Sechrist KR, Pender NJ. The Health-Promoting Lifestyle Profile: development and psychometric characteristics. Nurs Res. 1987;36(2):76-81.

19. Mohammadi Zeidi I, Pakpour Hajiagha A, Mohammadi Zeidi B Reliability and Validity of Persian Version of the Health-Promoting Lifestyle Profile. J Mazandaran Univ Med Sci. 2012;21(1):102-13.

20. Hyndman RJ, Booth H. Stochastic population forecasts using functional data models for mortality, fertility and migration. Int JForecasting. 2008;24(3):323-42.

21. Lin YH, Tsai EM, Chan TF, Chou FH, Lin YL. Health promoting lifestyles and related factors in pregnant women. Chang Gung Med J. 2009;32(6):650-61. 